\title{
Cutaneous Blastomycosis Mimicking Breast Malignancy
}

\author{
Rose Chisenga $^{1}$, Tulika Chatterjee ${ }^{1}$, Zita Erbowor-Becksen ${ }^{1}$, Pranitha Kovuri ${ }^{1}$, Abuzar A. Asif ${ }^{1}$ \\ 1. Internal Medicine, University of Illinois College of Medicine, Peoria, USA
}

Corresponding author: Rose Chisenga, rose.chisenga@osfhealthcare.org

\begin{abstract}
Blastomycosis is a fungal infection caused by Blastomyces dermatitidis. While blastomycosis can cause systemic infection affecting multiple organs, localized blastomycosis of the breast is uncommon. Here, we report the case of a 50-year-old female with a localized left breast growth which started as a nodule and later ulcerated extensively. Although her clinical picture raised concerns for breast malignancy, workup revealed cutaneous blastomycosis with superimposed methicillin-susceptible Staphylococcus aureus and Klebsiella oxytoca infection. Interestingly, there was no evidence of pulmonary disease on CT chest imaging. She was treated with Amphotericin B for seven days and discharged on oral Itraconazole for nine months. Additionally, she received amoxicillin-clavulanate for her bacterial superinfection. On the six-month followup, the patient showed significant improvement. Blastomycosis can mimic several diseases including malignancy, pyoderma gangrenosum, and mycobacterial and bacterial infections leading to delayed diagnosis and treatment.
\end{abstract}

Categories: Dermatology, Internal Medicine, Infectious Disease

Keywords: cutaneous blastomycosis, breast malignancy, blastomycosis, infection, mimic

\section{Introduction}

Blastomycosis, caused by Blastomyces dermatitidis, is a common endemic mycosis that occurs predominantly in North America including the northcentral, midwestern, and southern states of the United States [1]. The annual incidence of blastomycosis in the United States has been estimated at 1-40 cases per 100,000; however, as only a few states report it, the true annual incidence remains unknown [2]. The primary infection mainly involves the lungs. Most infections are either asymptomatic or accompanied by mild respiratory symptoms that are usually attributed to nonfungal respiratory conditions [1]. The primary pulmonary infection can subsequently spread hematogenously to the skin, bone, genitourinary system, and central nervous system (CNS). Cutaneous cases of blastomycosis usually originate from a pulmonary site regardless of whether a patient presents with a clinically apparent lung infection; however, in rare cases, direct cutaneous inoculation with $B$. dermatitidis has been reported [3]. Blastomycosis is a great mimicker of various medical conditions and pathologies, including neoplasia, mycobacterial infections, immunological skin disorders, and other mycoses, which can make diagnosis even more challenging [4].

Review began 07/21/2021 Review ended 08/15/2021 Published 08/18/2021

(c) Copyright 2021

Chisenga et al. This is an open access article distributed under the terms of the Creative Commons Attribution License CC-BY 4.0., which permits unrestricted use, distribution, and reproduction in any medium, provided the original author and source are credited.

\section{Case Presentation}

A 50-year-old female with a past medical history of type 2 diabetes mellitus, hypertension, morbid obesity (body mass index $51.4 \mathrm{~kg} / \mathrm{m}^{2}$ ), and hyperlipidemia presented with a left breast growth that she had first noticed a year ago. It started as a nodule which ulcerated after three weeks (Figure 1). The area became progressively tender, erythematous, and eventually affected more than half of her breast. She received multiple outpatient trials of topical and oral antibiotics without improvement. The patient had obtained a mammogram as an outpatient which reported the breast abnormality as a "superficial skin lesion without any breast parenchymal abnormality" (Figures $2 A, 2 B$ ). She also reported a foul-smelling discharge and occasional left breast itchiness lasting two to three weeks prior to presentation. The patient denied any history of fever, night sweats, weight loss, trauma to the breast, or any other skin abnormalities. She had no history of cough, hemoptysis, or other pulmonary symptoms. Her family history was remarkable for breast carcinoma in her grandmother diagnosed after age 60. She had predominantly lived in the midwestern part of the United States but denied recent travel, sick contacts, hiking to wooded areas, or insect bites. She had healthy cats and dogs for pets with no reported animal bites. On physical examination, the patient's vital signs were within normal limits and she had a verrucous-appearing growth on her left breast measuring approximately $20 \mathrm{~cm} \times 10 \mathrm{~cm}$ with raised irregular borders and a foul-smelling discharge. There was a small rim of peri-lesion erythema, and the lesion eroded the areola with no nipple retraction (Figure 3). Palpation revealed no breast lumps or lymphadenopathy. 


\section{Cureus}

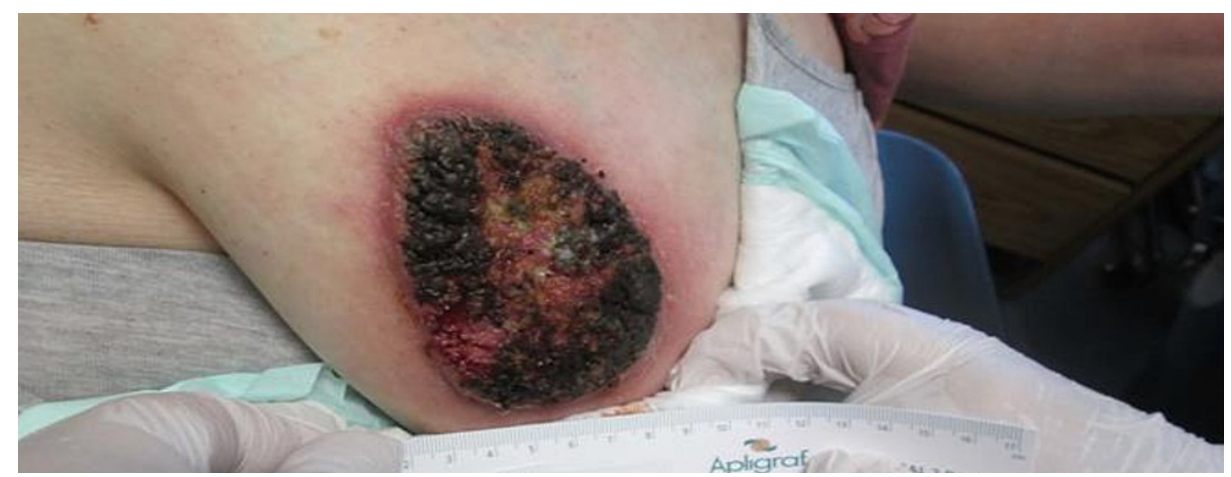

FIGURE 1: Left breast lesion prior to hospitalization.

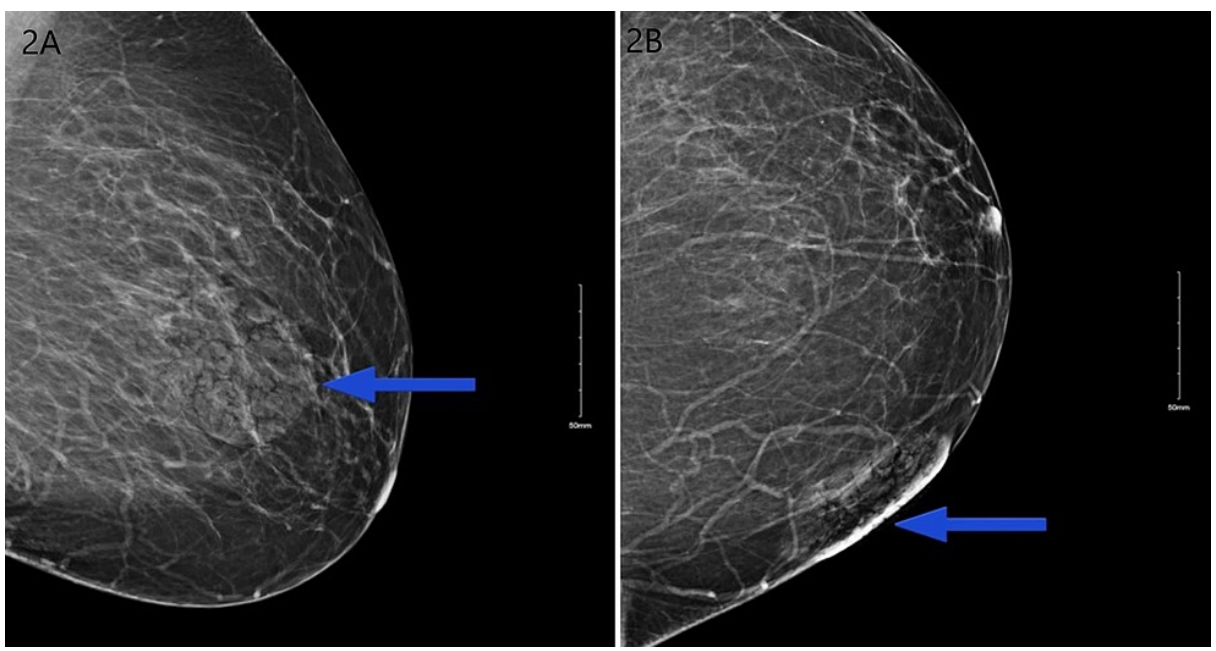

FIGURE 2: Mammogram showing breast lesion confined to the skin (lesion is marked with a blue arrow).

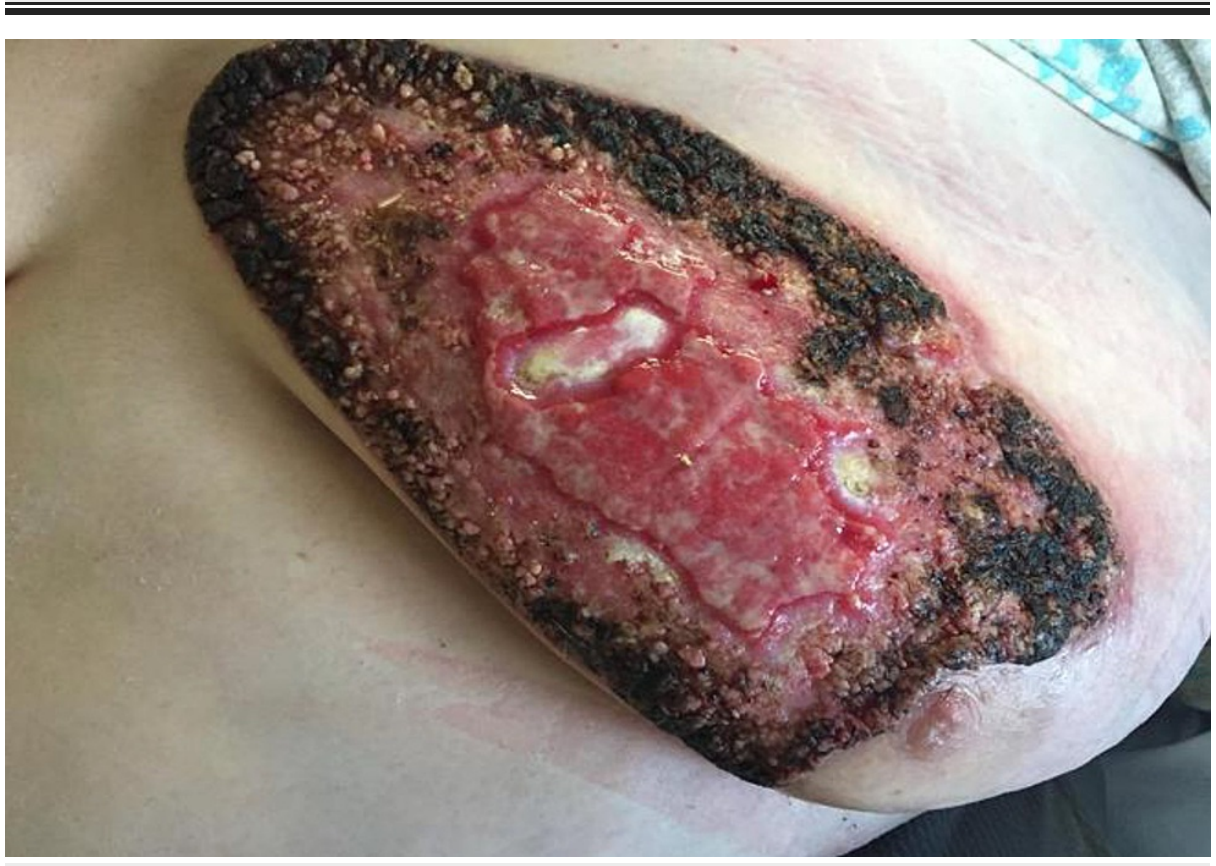

FIGURE 3: Left breast lesion on the day of hospitalization. 


\section{Cureus}

Initial laboratory tests revealed no significant findings except for an elevated C-reactive protein and a positive serum Blastomyces quantitative antigen test (Table 1). Blood fungal cultures were negative. Biopsy and culture of the breast tissue confirmed blastomycosis with superimposed bacterial infection (methicillinsusceptible Staphylococcus aureus and Klebsiella oxytoca). To further rule out systemic blastomycosis, chest and brain imaging were scheduled. CT chest showed no evidence of pulmonary fungal disease (Figure 4). MRI brain was not obtained because of the patient's severe claustrophobia. It is important to note that the patient had no neurological symptoms.

\begin{tabular}{|c|c|c|}
\hline Laboratory test & Value & Reference range \\
\hline White blood cell count & $7.94 \times 10^{3} / \mu \mathrm{L}$ & $4.00-12.00 \times 10^{3} / \mu \mathrm{L}$ \\
\hline Red blood cell count & $5.11 \times 10^{6} / \mu \mathrm{cL}$ & $3.80-5.30 \times 10^{6} / \mu \mathrm{L}$ \\
\hline Hematocrit & $42.8 \%$ & $36.0-47.0 \%$ \\
\hline Hemoglobin & 13.9 g/dL & $12.0-15.8 \mathrm{~g} / \mathrm{dL}$ \\
\hline Mean corpuscular volume & $83.8 \mathrm{fL}$ & 82.0-96.0 fL \\
\hline Platelet count & $225 \times 10^{3} / \mu \mathrm{L}$ & $140-440 \times 10^{3} / \mu \mathrm{L}$ \\
\hline Neutrophils & $65.1 \%$ & $47.0-73.0 \%$ \\
\hline Lymphocytes & $26.6 \%$ & $18.0-42.0 \%$ \\
\hline Monocytes & $6.7 \%$ & $4.0-12.0 \%$ \\
\hline Eosinophils & $1.1 \%$ & $0.0-5.0 \%$ \\
\hline Basophils & $0.5 \%$ & $0.0-1.0 \%$ \\
\hline Absolute neutrophils & $5.17 \times 10^{3} / \mu \mathrm{L}$ & $1.60-7.70 \times 10^{3} / \mu \mathrm{L}$ \\
\hline Absolute lymphocytes & $2.11 \times 10^{3} / \mu \mathrm{L}$ & $1.30-3.20 \times 10^{3} / \mu \mathrm{L}$ \\
\hline Sodium & $134 \mathrm{mmol} / \mathrm{L}$ & $136-145$ mmol/L \\
\hline Potassium & $3.7 \mathrm{mmol} / \mathrm{L}$ & $3.5-5.1 \mathrm{mmol} / \mathrm{L}$ \\
\hline Creatinine & 0.73 & $0.60-1.00 \mathrm{mg} / \mathrm{dL}$ \\
\hline C-reactive protein & $4.51 \mathrm{mg} / \mathrm{dL}$ & $<0.50 \mathrm{mg} / \mathrm{dL}$ \\
\hline Histoplasma capsule H Ab & Negative & \\
\hline Histoplasma capsule M Ab & Negative & \\
\hline Coccidioides immitis Ab & Negative & \\
\hline Blastomyces dermatitidis Ab & Negative & \\
\hline Aspergillus fumigatus $A b$ & Negative & \\
\hline Beta-D-glucan $(1,3)$ (Fungitell) & Negative & \\
\hline Serum Blastomyces quantitative Ag & Positive & \\
\hline HIV 1, 2 Ag Ab screen & Negative & \\
\hline
\end{tabular}

\section{TABLE 1: Laboratory findings.}

$\mathrm{Ab}$ : antibody; Ag: antigen 


\section{Cureus}

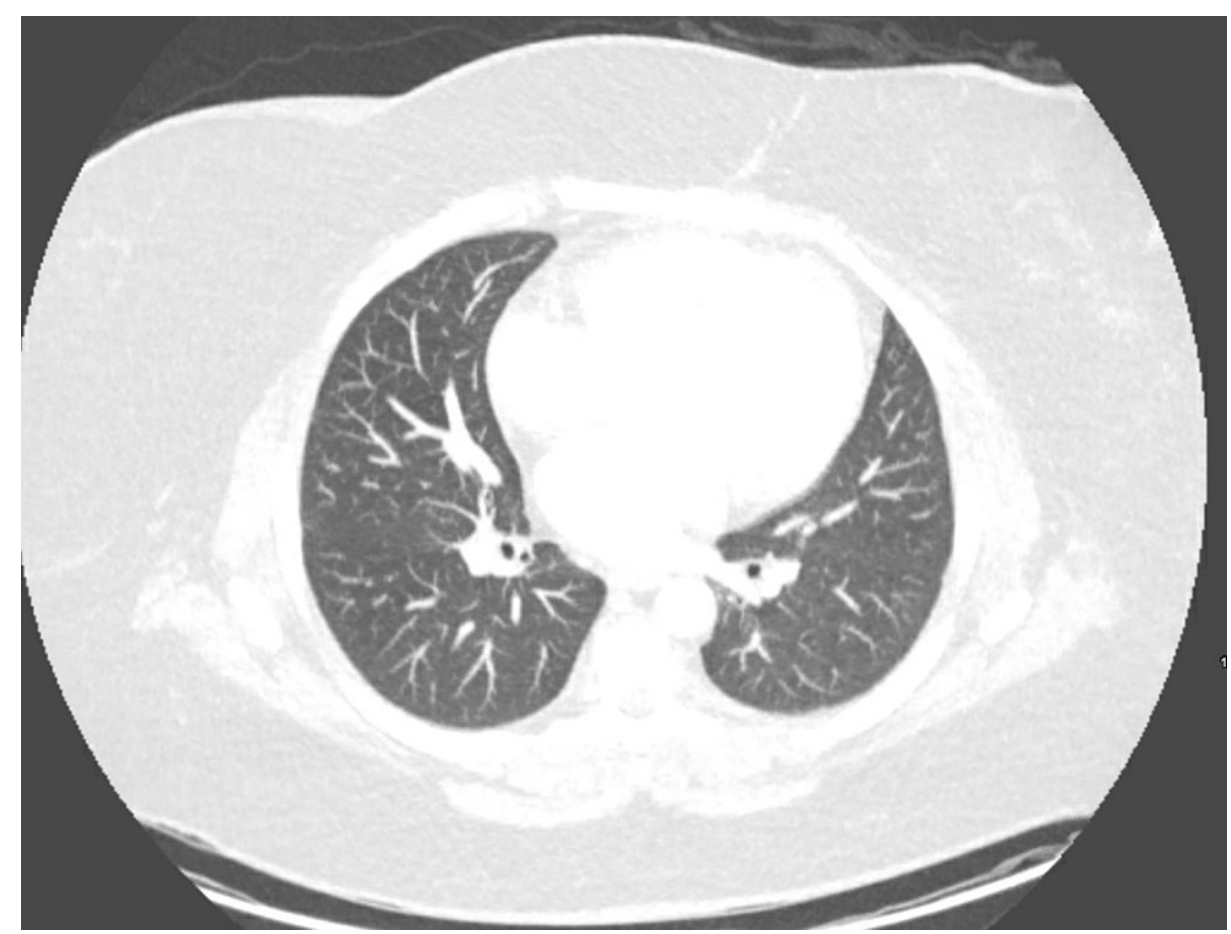

FIGURE 4: Transaxial chest CT with no evidence of pulmonary fungal disease.

CT: computed tomography

The patient was treated with Amphotericin B for seven days and discharged on oral Itraconazole. Additionally, she received amoxicillin-clavulanate for 10 days for superimposed bacterial infections.

On the six-month follow-up, the patient showed significant improvement with near resolution of the skin abnormality while on antifungal therapy, and the course of Itraconazole was reduced to a total of nine months.

\section{Discussion}

Blastomycosis mimics several diseases and can be easily misdiagnosed as neoplasia, pyogenic gangrenosum, nocardiosis, mycobacterial infection, immunologic skin disorders, and other mycoses [4]. In the spectrum of the presentation of blastomycosis, breast involvement is uncommon, as noted in the literature [5-9].

The most common clinical presentation of blastomycosis is pneumonia though pulmonary infiltrates may be found on routine chest radiographs of patients with blastomycosis despite a lack of respiratory complaints $[6,8]$. Cutaneous involvement is the next most common clinical presentation [6]. Cutaneous lesions of blastomycosis may be verrucous or ulcerative in nature [6,9]. Verrucous lesions are raised and crusted with irregular sharp borders and underlying subcutaneous abscesses [10]. Skin ulcerations develop due to spontaneous rupture of the subcutaneous abscesses [6]. Our patient initially reported a "pimple-like" skin abnormality, which was likely a subcutaneous blastomycosis abscess which later ruptured and ulcerated. Edges of blastomycosis cutaneous ulcers are sharp and raised along with central exudative regions, as was evident in our patient's breast lesion.

Most cases of cutaneous blastomycosis occur following the lymphohematogenous spread of pulmonary blastomycosis. With time, the patient develops an immune response which leads to pyogranulomatous changes at the site of primary or secondary inoculation which is followed by the formation of noncaseating granulomas [10]. About half of secondary cutaneous cases of blastomycosis have no evidence of pulmonary infection at the time of diagnosis and have normal chest radiographs. Most patients with cutaneous blastomycosis who have no evidence of pulmonary infection are presumed to have had a subclinical pulmonary infection or an asymptomatic phase that had already resolved. Because cutaneous blastomycosis is usually associated with negative chest radiography, it is difficult to distinguish between primary and secondary cutaneous blastomycosis with a resolved or subclinical pulmonary phase of the disease [11]. In this case, it was difficult to determine whether it was a case of primary or secondary cutaneous blastomycosis. 
As noted in our case, diagnosis of cutaneous blastomycosis can be challenging. Urine and serum blastomycosis antigen tests have good sensitivity but are not as specific due to cross-reactivity with other systemic mycoses, particularly histoplasmosis. Microscopic visualization and tissue culture are more specific; however, tissue culture can take up to five weeks causing a delay in diagnosis. Microscopic visualization is timely but less sensitive than culture, requiring a good sample size and local expertise. Although polymerase chain reaction and DNA sequencing tests such as Karius are newer noninvasive diagnostic modalities that can be used, they need further large-scale investigation to establish their realworld clinical impact. It is important to utilize multiple testing modalities available for accurate and timely diagnosis of cutaneous blastomycosis [12-14].

\section{Conclusions}

This case elaborates how cutaneous blastomycosis can mimic different pathologies including malignancy depending on its location. Skin abnormalities have been reported in $40-80 \%$ of blastomycosis cases. The unusual location of the lesion on the breast made the diagnosis challenging in our case. This case emphasizes the importance of combining antigen test results, prompt tissue biopsy, and culture whenever fungal mycoses are suspected. Treatment with Amphotericin B followed by Itraconazole has been shown to be highly effective. Even though most cases respond well to oral Itraconazole for 6-12 months, disseminated blastomycosis cases including those involving CNS require intravenous Amphotericin B before starting oral Itraconazole.

\section{Additional Information \\ Disclosures}

Human subjects: Consent was obtained or waived by all participants in this study. Conflicts of interest: In compliance with the ICMJE uniform disclosure form, all authors declare the following: Payment/services info: All authors have declared that no financial support was received from any organization for the submitted work. Financial relationships: All authors have declared that they have no financial relationships at present or within the previous three years with any organizations that might have an interest in the submitted work. Other relationships: All authors have declared that there are no other relationships or activities that could appear to have influenced the submitted work.

\section{References}

1. Smith JA, Kauffman CA: Blastomycosis. Proc Am Thorac Soc. 2010, 7:173-80. 10.1513/pats.200906-040AL

2. G Caldito E, Ajiboye O, Flores E, Antia C, Demarais P: The importance of skin exam in chronic pulmonary blastomycosis. IDCases. 2020, 20:e00812. 10.1016/j.idcr.2020.e00812

3. Gray NA, Baddour LM: Cutaneous inoculation blastomycosis. Clin Infect Dis. 2002, 34:E44-9. $10.1086 / 339957$

4. Richels L, Holfeld K: An uncommon infectious etiology in an unlikely geographic location: a case report of cutaneous blastomycosis in Saskatchewan. SAGE Open Med Case Rep. 2019, 7:2050313X19897716. 10.1177/2050313X19897716

5. MacFadden DR, Gold WL, Richardson SE, Bunce PE: A breast mass in a 56-year-old man . CMAJ. 2011, 183:1875-8. 10.1503/cmaj.110953

6. Propeck PA, Scanlan KA: Blastomycosis of the breast. AJR Am J Roentgenol. 1996, 166:726. 10.2214/ajr.166.3.8623669

7. Farmer C, Stanley MW, Bardales RH, Korourian S, Shah H, Bradsher R, Klimberg VS: Mycoses of the breast: diagnosis by fine-needle aspiration. Diagn Cytopathol. 1995, 12:51-5. 10.1002/dc.2840120112

8. Seymour EQ: Blastomycosis of the breast. AJR Am J Roentgenol. 1982, 139:822-3. 10.2214/ajr.139.4.822

9. Salfelder K, Schwarz J: Mycotic "pseudotumors" of the breast. Report of four cases . Arch Surg. 1975, 110:751-4. 10.1001/archsurg.1975.01360120069013

10. Bradsher RW Jr: The endemic mimic: blastomycosis an illness often misdiagnosed . Trans Am Clin Climatol Assoc. 2014, 125:188-202; discussion 202-3.

11. Mason AR, Cortes GY, Cook J, Maize JC, Thiers BH: Cutaneous blastomycosis: a diagnostic challenge. Int J Dermatol. 2008, 47:824-30. 10.1111/j.1365-4632.2008.03732.x

12. Saccente M, Woods GL: Clinical and laboratory update on blastomycosis . Clin Microbiol Rev. 2010, 23:36781. 10.1128/CMR.00056-09

13. Hogan CA, Yang S, Garner OB, et al.: Clinical impact of metagenomic next-generation sequencing of plasma cell-free DNA for the diagnosis of infectious diseases: a multicenter retrospective cohort study. Clin Infect Dis. 2021, 72:239-45. 10.1093/cid/ciaa035

14. Hage CA, Carmona EM, Epelbaum O, et al.: Microbiological laboratory testing in the diagnosis of fungal infections in pulmonary and critical care practice. An Official American Thoracic Society clinical practice guideline. Am J Respir Crit Care Med. 2019, 200:535-50. 10.1164/rccm.201906-1185ST 